\title{
ACEDIA: \\ THE ETIOLOGY OF WORK-ENGENDERED DEPRESSION
}

\author{
by \\ Steven J. Bartlett \\ Visiting Scholar in Psychology, Willamette University \\ and \\ Senior Research Professor, Oregon State University \\ Website: http://www.willamette.edu/ sbartlet
}

KEYWORDS: acedia, teacher burnout, teaching of liberal arts, liberal arts values

This paper was originally published in New Ideas in Psychology, Vol. 8, No. 3, 1990, 389-396. The original paper may be obtained from http://www.journals.elsevier.com/new-ideas-in-psychology/. This electronic version supplements the journal's text with internet-searchable keywords and is the author's original version. For readers wishing to cite the pagination in the journal, the journal's page numbering is indicated in braces: for example, $\{390\}$ appears at the beginning of the journal's text on page 390 .

The author has chosen to re-issue this work as a free open access publication under the terms of the Creative Commons Attribution-NonCommercial-NoDerivs license, which allows anyone to distribute this work without changes to its content, provided that both the author and the original URL from which this work was obtained are mentioned, that the contents of this work are not used for commercial purposes or profit, and that this work will not be used without the author's or his executor's permission in derivative works (i.e., you may not alter, transform, or build upon this work without such permission). The full legal statement of this license may be found at

http://creativecommons.org/licenses/by-nc-nd/3.0/legalcode

(c) $(1) \Theta($ 


\title{
ACEDIA: THE ETIOLOGY OF WORK-ENGENDERED DEPRESSION
}

\author{
by \\ Steven J. Bartlett \\ Research Professor, Oregon State University, \\ Corvallis, Oregon 97331-6205, U.S.A. \\ and \\ Visiting Scholar in Psychology and Philosophy, \\ Willamette University, Salem, Oregon 97301, U.S.A.
}

\section{ABSTRACT}

There has been a general failure among mental health theorists and social psychologists to understand the etiology of work-engendered depression. Yet the condition is increasingly prevalent in highly industrialized societies, where an exclusionary focus upon work, money, and the things that money can buy has displaced values that traditionally exerted a liberating and humanizing influence. Social critics have called the result an impoverishment of the spirit, a state of cultural bankruptcy, and an incapacity for genuine leisure. From a clinical perspective, the condition has been diagnosed as widespread narcissism and obsessive work.

Acedia, a concept developed by the Scholastics, throws clarifying light on the origin of this form of depression.

"I consider reality to be the thing one need concern oneself about least of all, for it is, tediously enough, always at hand while more beautiful and necessary things demand our attention and care."

— Hermann Hesse, 1955, "My Life: A Conjectural Biography"

Clinical depression at present is treated in two main, often complementary, ways: Through pharmacological intervention, and by psychotherapy. Psychotherapeutic treatment may involve any of a number of individual approaches, ranging from psychoanalysis to cognitive therapy to behavior change. Among current therapies are several approaches that focus special attention on the central role of a person's attitudes and values in both the genesis and the amelioration of depression.

These psychotherapies include Alfred Adler's individual psychology (1926/1912, 1927, 1964/1929), George Kelly's personal construct theory (1955, 1956), Viktor Frankl's logotherapy (1959, 1965), and Albert Ellis' cognitive therapy (1961, 1973, 1975). A therapist who subscribes to any of these points of view will, in general, treat clinical depression by attempting to make explicit and then work to strengthen or change the patient's, or client's, most basic attitudes about living. Depression is believed to be the result of a fundamental mismatch between a patient's beliefs and 
values, and the realities and goals with which he or she must deal. Such a state of affairs brings about chronic frustration, emotional suffering, and potential demoralization. More specifically, these theories of psychotherapy claim that clinical depression is brought about by a group of "basic mistakes" in perceiving the world (Adler), by a self-defeating or self-confounding way of construing the world (Kelly), by an inadequate or un realized framework of meaning (Frankl), or by an irrational set of expectations (Ellis). $\{390\}$

Adler, Kelly, Frankl, Ellis, and others situate psychotherapy within the personal framework of meaning or the internal logic and belief system of their individual patients. Their psychotherapies are, to varying degrees, forms of phenomenological psychology, which began with Brentano (1924, 1925, 1928) and reached perhaps its most suggestive development in the phenomenological psychiatry of J. H. van den Berg (1955).

The locus of depression for these phenomenological theories is wholly internal. According to them, depression is born and is maintained thanks to an internal dynamic that renders a person vulnerable to demoralization and despair. Here, Adler, Kelly, Frankl, and Ellis refuse to apply the category of disease to psychological disorders: Their clients are not "sick," for they believe there is no "disease" there to be treated; the problems they face are problems of living. This is Thomas Szasz's criticism of medical psychiatry: It frequently reifies problems of living into varieties of illness. (Miller 1983: 290; Szasz 1961/57). In doing this, it makes what philosopher Gilbert Ryle called a "category mistake," or it falls victim to what Whitehead named the "fallacy of misplaced concreteness." The mistake, or the fallacy, is that we forget that a metaphor is not reality.

In this paper, we look at a variety of depression that was first studied by the medieval Scholastics. Their frame of reference resembles that of phenomenological approaches to depression, but unlike them it suggests that a person's attitudes and values do not directly of themselves give rise to the form of depression with which they were concerned. Instead, the Scholastics argued that this variety of depression is, we might say, negatively defined by a person's values and belief system. It arises due to the exclusionary nature of the set of values to which a per son is committed: It results, that is to say, from what his attitudes neglect or omit. In other words, this type of depression is, as we will see, brought about by a deficiency of values.

Obsession with work and money has overtaken the societies of highly industrialized countries. Work has always been a condition of living, but in the last half century work has become so central in our preoccupations that other values have been displaced.

This single-mindedness and exclusive focus upon work and the monetary value of time form a social environment in which psychologists increasingly see a certain manifestation of depression. It is a variety of depression whose genesis we have failed to under stand clearly, and which we have been unable to appreciate for what it tells us about ourselves.

Few concepts drawn from medieval moral theology have direct bearing on the diagnostic vocabulary of DSM-III. Acedia is no exception. It is a rather simple idea, one that was apparently easy to grasp at the height of the Middle Ages. Yet today, though it is still an uncomplicated notion, the meaning of acedia is so remote from our modern daily cares and professional concerns that it is hard to under stand. But effort here is worth while, if only to help us gain a broader and perhaps a more humane understanding of depression.

\section{WORK AND CULTURAL BANKRUPTCY}

In highly industrialized societies like those in western Europe and America, $\{391\}$ the values that have come to supersede all others are money, material comfort, and financial security (the assurance that the first two values will be satisfied in the future). Values of monetary relevance appear on the individual level for the majority of people in the form of a pronounced and single-minded, 
obsessional concern to acquire and then to remain in a well-paying job. What frequently results is a condition that medieval moral theologians called acedia. ${ }^{1}$

Acedia is the state of mind that comes about when a per son has lost his or her capacity for leisure, where leisure is under stood in a sense no longer familiar to us to day. A certain in capacity develops and becomes firmly established, whose existence contemporary industrial society is able to recognize only with consider able difficulty.

The values of work and money, like the limited cares of any exclusive preoccupation, blind its adherents to alternative values. They narrow the scope of a man's concerns; he becomes wholly absorbed in his demands for immediate gratification, and in worry over future gratification. When this happens, medieval theologians recognized "an impoverishment of the soul." We call much the same condition work-related depression and in some cases "career burnout" (Pines \& Aronson 1988; cf. Rohrlich 1980), but in so doing, as I hope to make clear, we lose much of the explanatory power of the medieval view.

The logic of usage that underlies the meaning of acedia is alien to us today: A logician would say it is "three-valued," whereas our customary logic is bivalent, recognizing only the two "values," truth and falsity. In a two-valued logic, a term has one opposite, its negation. In a three-valued logic, a term may have two "opposites," each being the contrary of the other.

Today, we recognize two extremes: On one side, we locate work and the desirable traits that accompany it, such as diligence, industry, competitiveness, ambition, etc. On the other side, we situate leisure, having time on one's hands, being idle, even lazy — in short, having time away from work. Time away from work is useful to the extent and, we are now increasingly inclined to feel, virtually only to the extent, that it serves as a restorative which, after two weeks, enables a man or a woman to return to money-making work with renewed energy and zeal.

It is impossible to understand acedia in this context. To understand the medieval conception, we need to think in three-valued terms: Work, diligence, industry make up one extreme. Idle ness, laziness, and time free from the demands of work make up another. And leisure, in the special meaning the Scholastics associated with the word, is separate from both of these. In the medieval view, acedia is the opposite of leisure; it is an in ability to experience $\{392\}$ leisure. But it is not idleness (or laziness). Idleness is contrary to work, while leisure is the contrary both of idleness and of work.

In our bivalent attitude toward work, not only do we fall victims to acedia, but we cannot realize that this has happened to us. - This is not verbal trickery, but a fact we should be able to appreciate, if we will bear with the three-valued medieval view a little longer.

Leisure meant something specific to the medieval mind. It was not synonymous, as we have said, with idleness or taking a vacation. Leisure was instead associated with culture, with the cultivation of the spirit, with cultus. ${ }^{2}$ The Scholastics believed that man's capacity for leisure was one with his ability to be spiritual, to be conscious of himself as a divine creation, to cultivate spirituality within him self, and to accept his place in a universe that contains both matter and "higher values," those that transform his daily life and his human suffering.

These values they thought were higher because they be stowed upon everyday life a significance

1 The medieval Schoolmen were primarily concerned with acedia as the ultimate cause of "work for work's sake." In this, they are followed by Josef Pieper, one of the few con temporary thinkers who has given attention to acedia. (See the following note.)

Emphasis in this article is on the reverse, psychologically important relationship, i.e., on how an ethic of work for its own sake leads to acedia. A complete account should recognize that there is a mutually self-sustaining interaction between an exclusionary focus on work, on the one hand, and acedia on the other. Each encourages and helps to perpetuate the other.

${ }^{2} \mathrm{I}$ am indebted in this analysis to several authors, principal among them Josef Pieper. See Pieper (1963/1948, 1986/1977), Jünger (1934), and de Grazia (1962). 
that transcended the workaday world. In the same way, higher education was called higher be cause its aim was to encourage cultivation, specifically the cultivation of non-useful things. The ends of "higher education" had nothing to do with utilitarian pursuits, nothing to do with the acquisition of skills necessary to get a well-paying, secure job. Higher education was devoted to those things that are of value "in and of themselves," as it was then commonplace to say.

Leisure, then, was an attitude of mind, an attitude of silent affirmation, of acquiescence in a created world in which a man is and cannot but be at home, from birth and throughout his life. This form of "letting go" is not non-activity. Leisure is active contemplation, enjoyment, and appreciation of being and of being oneself. To be capable of leisure requires that a man or woman affirm his or her own sense of identity, apart from a role as worker, father, mother, or consumer. To be incapable of this, is acedia.

Acedia, in short, is an inability to see reality in other than mundane and mediocre ways. It is an inability to perceive reality under the guise of the transformation that "higher values" make possible. During the Middle Ages, these values were rooted in religion - as it happened, in Christianity. But higher values need not be Christian, or even theistic. Reality can be transformed by myth, by poetry, by music, art, philosophy, by abstract theoretical re search that has no practical application in view, or by imagination. When these powers of transformation diminish or are lost, men's minds are blunted, and they begin to suffer from a disability of values. Acedia is just such a disability.

\section{THE SYMPTOMS OF $A C E D I A$}

In the impoverished state of mind brought about by an exclusionary relish for work and its financial rewards, acedia leads to despair-to an unwillingness and an inability to be fully human. It is a state of mind without hope, a condition of demoralization that is an impasse to realizing one's full human potential.

The Scholastics realized that despair is a block to growth: in the words of Saint Paschasius $\{393\}$ Radbert, despair "closes the door" (1857-1866: liber II, caput VI, 2). As with leisure, the medieval meaning of despair is more comprehensive than is ours today. It is not sadness or grief, but a barrier that stands between the man or woman who is slave to the world of work, and higher values. It handicaps man's ability to transform the mundane, to apprehend what stunted, mediocritized man cannot see or appreciate.

The over-emphasis of our society upon work and the things money can acquire has exactly this stunting effect. Our perspective becomes foreshortened: "greater" and "less than" are reduced to inconsequentialities. The great no longer stand out, the ordinary encompasses all, and in difference replaces the respect that we once bestowed on the extraordinary.

Aquinas identified the other members of acedia's family, the psychological sequelae of this selfchosen narrowing of the human outlook. They are the filiae acediae, the partners and companions of despair. (Aquinas 1949: Vol. II, 4; and 1921-1925: Part II of the Second Part, Ques. 35, Article 4, answer to the Second Objection.) They spell out, with greater clarity and in more de tail than DSMIII, what work-engendered depression means, in human terms.

In addition to despair, acedia leads to what Aquinas called evagatio mentis, an uneasy restlessness of mind that expresses itself in

- verbositas — a need for the distraction and stimulus of unbridled, mindless talk;

- inquietudo—or inner restlessness;

- instabilitas loci vel propositi—instability of place or purpose;

- curiositas—an unfocused, unanchored, indiscriminate surface interest in any and all things; 
and

- importunitas - the urge to scatter oneself in many pursuits.

In addition to despair and restlessness, the symptoms of acedia include

- torpor-repudiation, indifference toward, and neglect of higher values;

- pusillanimitas — antagonism toward higher values;

- rancor-resentful rebellion against those who represent and seek to cultivate higher ends; and, finally,

- malitia - the pure malice that reflects a deliberate choice in favor of evil, and a deep-seated commitment to hatred for whatever may be capable of elevating man above the trivial, the fatuous, the superficial.

This list of the symptoms of acedia could easily stand as a psychological profile of industrial society: The medieval terms have their unambiguous correlates in the tense restlessness, angry rebelliousness, embrace of mediocrity, and intellectual lethargy and demoralization that permeate so much of our society.

Acedia is, then, a disability of values. Higher values are amputated, yet the amputee is adamant that he is sound of mind and body. The dynamic of his life-world rein forces his belief. His monadic universe becomes self-encapsulated; it is the autistic world of narcissism. ${ }^{3}$

Many who are trapped in this confining world of workaday values are $\{394\}$ unhappy-unhappy to the point of clinical depression. Some are unable to sustain their hollow drive to work, and collapse in fatigue, despair, and perplexed disillusionment. Clinical psychology is inclined to say of them that they have acquired a certain disorder of adaptation, to which we'll turn our attention in a moment, and more specifically that they have developed an inhibition to continue working. They are the most evident casualties of a work ethic gone mad.

\section{ACEDIA: MORAL FAILURE OR PSYCHIATRIC DISORDER?}

The psychological result of a work- and materialististically-obsessed society surrounds us. Acedia is boredom, despair, idleness. It takes the form of restless ness, violence, and anger. It is an unrecognized sadness that has diffused throughout our industrialized world of high techno logy, a world in which art, poetry, music, philosophy, and even pure theory and prayer have in the main become no more than distractions from an obsessive work ethic, offering no more than temporary escape, time out, from our complete absorption of mind, energy, and spirit in work and material consumption. The disorder we face is the result of a spreading moral failure, sustained by a loss of hope before an all-consuming epidemic of work and materialism.

It is both significant and ironic that clinical psychology has now created a category in which to accommodate those who, overcome by the barrenness of the world of total work, be come conscious of its depressive nature, and feel the full weight of its baseless dedications. This is the "disorder" DSM-III calls an "adjustment disorder, with work inhibition" (American Psychiatric Association 1987, code 309.23). It is the closest our current classification of psychological disorders comes to acknowledging the contributing role to human suffering of a work ethic that has gone out of control. The DSM-III diagnostic description is all too short, and not especially enlightening:

${ }^{3}$ On the willful self-confinement of clinical narcissism, see Bartlett (1986). 
The essential feature of this disorder is a maladaptive reaction to an identifiable psychological stressor.... The maladaptive nature of the reaction is indicated...by impairment in occupational (including school) functioning... [T] he predominant manifestation is an inhibition in work...occurring in a person whose previous work...performance has been adequate. Frequently there is also a mixture of anxiety and depression.

\section{TREATMENT OF WORK-ENGENDERED DEPRESSION}

There is, indeed, as Thomas Szasz (1961/57) inveighs, a temptation for society to justify its prejudices in its classification of psychological disorders. In a society consecrated to an ethic of universal work, leisure-beyond minimal, regular restorative vacations, which we accept as we do the need for the other type of regularity-inevitably must come to be felt as a contrary value. In our devotion to utility and technology we can find no room for culture in its root meaning.

Leisure and idleness are therefore equated, and in that equating we have allowed non-utilitarian values, the antigens against mediocrity, to slip away. Because of our loosened grip on higher ends we live in a time when "culture" is $\{395\}$ glorified as a kind of trivial pursuit, at the competent hands of men like E. D. Hirsch, Jr. (1987).

In this social context, not only is work-engendered depression encouraged, but finding a cure for it is made all the more difficult.

There is a certain naïveté and charm about the views of the medieval theologians; certainly their outlook fit a society very different from ours today. The responsibility fell to men in this distant past to try to articulate how men should live in order to live in the best way possible. To do this in a reasonable or convincing fashion, they needed first to have a vision of the meaning of human life. This they did possess, often to a dogmatic and didactic fault. Yet perhaps it takes such excess to persuade men of little faith.

Treatment for work-engendered depression requires just such a prescription for living. It requires the cultivation of values beyond utility that can balance an unbalanced obsession with jobs, money, and things. Therapy for work-engendered depression cannot be effective as long as acedia is identified with idleness, as long as we construe depression due to the aridity of work without end as "an adjustment disorder, with work inhibition." To treat the variety of depression that is acedia, we need to relinquish our fast hold upon the values that constrain us to lives devoted to serving Mammon. We must be prepared to lift the blinders from our own eyes in order to help our clients and patients overcome the debilitating blindness that our worker state has produced in them. 


\section{REFERENCES}

Adler, Alfred (1926/1912). The Neurotic Constitution. New York: Dodd Mead. Originally published 1912.

Adler, Alfred (1927). The Practice and Theory of Individual Psychology. New York: Harcourt Brace.

Adler, Alfred (1964/1929). Problems of Neurosis: A Book of Case-Histories. New York: Harper. Originally published 1929.

American Psychiatric Association (1987). Diagnostic and Statistical Manual of Mental Disorders, Third Edition, Revised. Washington, D.C.: American Psychiatric Association.

Aquinas, St. Thomas (1912-1925). Summa Theologiae, 22 vols., translated by the English Dominican Fathers. London: Burns, Oates, and Washbourne, Ltd.

Aquinas, St. Thomas (1949). Questiones Disputatae de Malo in Quaestiones Disputatae, 2 vols. Rome: Marietti.

Bartlett, Steven J. (1986). Narcissism and Philosophy, Methodology and Science, Vol. 19, No. 1, pp. 16-26.

Brentano, Franz (1924, 1925, 1928). Psychologie vom empirishen Standpunkt, 3 vols. Leipzig: Felix Meiner.

de Grazia, Sebastian (1962). Of Time, Work, and Leisure. New York: The Twentieth Century Fund.

Ellis, Albert and R. A. Harper (1961). A Guide to Rational Living. Englewood Cliffs, New Jersey: Prentice Hall.

Ellis, Albert (1973). Humanistic Psychotherapy: The Rational-Emotive Approach. New York: McGraw-Hill.

Ellis, Albert and R. A. Harper (1975). A New Guide to Rational Living. Englewood Cliffs, N.J.: PrenticeHall.

Frankl, Viktor (1959). Man's Search for Meaning: An Introduction to Logotherapy. New York: Washington Square Press.

Frankl, Viktor (1965). The Doctor and the Soul. New York: Knopf. \{396\}

Hesse, H. (1955). (D. Lindley, Trans.). In W. Phillips \& P. Rahv (Eds.), Avon Book of Modern Writing (pp. 55-72). New York: Avon. (Original work published 1925.)

Hirsch, Eric Donald (1987). Cultural Literary: What Every American Needs to Know. Boston: Houghton Mifflin.

Jünger, Ernst (1934). Blätter und Steine. Hamburg: Hanseatische Verlagsanstalt.

Kelly, George A. (1955). The Psychology of Personal Constructs. New York: Norton.

Kelly, George A. (1956). Man's Construction of His Alternatives. In Gardner Lindzey, ed. Assessment of Human Motives. New York: Rinehart \& Winston, pp. 33-61. 
Miller, Jonathan (1983). States of Mind. New York: Pantheon.

Pieper, Josef (1963/1948). Leisure, the Basis of Culture, translated by Alexander Dru. New York: New American Library. Original published as Musse und Kult and $W$ as heisst Philosophieren? München: Käsel-Verlag, 1948.

Pieper, Josef (1986/1977). On Hope, translated by Mary Frances McCarthy. San Francisco: Ignatius Press. Original published as Über die Hoffnung. München: Käsel-Verlag, 1977.

Pines, Ayala and Elliot Aronson (1988). Career Burnout: Causes and Cures. New York: The Free Press.

Radbert, St. Pachasius (1857-1866). "De fide, spe et charitate," Opera Omnia, Patrologiae Cursus Completus, series graeca, J. P. Migne, ed., 161 vols. (Paris 1857-1866), Vol. 120, cols. 1387-1490.

Rohrlich, Jay B. (1980). Work and Love: A Crucial Balance. New York: Summit Books.

Szasz, Thomas Stephen (1961/1957). The Myth of Mental Illness: Foundations of a Theory of Personal Conduct. New York: Hoeber-Harper 1961. First published 1957.

van den Berg, J. H. (1955). The Phenomenological Approach to Psychiatry: An Introduction to Recent Phenomenological Psychopathology. Springfield, Illinois: Charles C. Thomas. 